\title{
Food Science Education, Research, and Professional Development
}

Phillip S Tong, California Polytechnic State University, San Luis Obispo, CA, USA

\section{Introduction}

In the Neolithic Age (10 000-3000 BC) humans transitioned from hunter-gatherer to cultivation of crops and domestication of animals for food. As they entered the Bronze Age, humans learned from practical experience about food preparation and shifted some of their plant and animal exploitations to make a variety of foods some of which could be stored for long periods. Although there was little in-depth understanding, food preparation including food fermentations and other practices would continue to improve and be refined through the 1600 s primarily through artisanal practices. But by the 1800 s the value of the science of food was demonstrated through the early systematic controlled studies which led to discoveries of canning by Nicolas Appert and subsequent advancement of our scientific knowledge of the role of microorganisms in food (wine) spoilage by Pasteur in the 1860s (Potter and Hotchkiss, 1986). These early scientific advances that led to improvements in food safety, quality, productivity, and shelf life solidified food science as a discipline and the modern food industry we employ today. Despite these advances, foodborne outbreaks were not uncommon in the late 1800s (Hardy, 1999). Meanwhile industrialization of the food system demanded trained professionals to run food plants and conduct the necessary product and process research and development. As a result, developments in food science education, research, and professional development occurred rapidly in the twentieth century. This article introduces the hierarchy of reference works that provide useful perspectives on the practice of discovery, transfer, and implementation that forms the body of our knowledge shaping food science.

\section{The Discipline and Food Science Education}

Early approaches to the development of food science education in the 1800 s were commodity-focused (e.g., dairy, fruits and vegetables, meats, etc.). However, by the early 1900s educators soon realized that the principles of preservation cut across all foods and people began to talk about food science and technology. So during the mid-to-late 1900s many food science and food science and technology departments were formed (Livingston, 1972). In association with the Institute of Food Technologists, program curricula were developed and recommended as guidelines for food science programs and have been periodically revised to best reflect the knowledge and skills to be successful as a practicing food scientist (Iwaoka, 2011). In the most recent recommendations there are expectations that each food science program deliver competencies of student learning in five main areas: (1) Food chemistry and analysis; (2) Food safety and microbiology; (3) Food processing and engineering; (4) Applied food science; and (5) Success skills with focus on communication.

Today, food science can be described as "the discipline in which the engineering, biological and physical sciences are used to study the nature of foods, the causes of deterioration, the principles underlying food processing, and the improvement of foods for the consuming public" and food technology (while often used interchangeably with food science) is described as "the application of food science to the selection, preservation, processing, packaging, distribution, and use of safe, nutritious, and wholesome food" (Institute of Food Technologists, 2011). The growing popularity of television shows on the Food Network and other major network stations have sparked a significant increase in student interest in the science of food. As a result there has been a recent increase in enrollment of food science students at universities throughout the world.

\section{Professional Development and Communication}

Because change is one constant we can expect in food science, continuous learning is an essential activity of any food scientist who wants to remain competent in his/her profession and keep up with a dynamic marketplace. Investments in continuous learning can encourage creativity, foster positive team dynamics, insure best practices, and contribute to business success. Workshops, symposia, Webinars, and short courses offered by universities, private companies, associations, and consulting groups provide a wide range of opportunities for professional development. Attending annual meetings of scientific associations provide opportunities for food science professionals to interact and network with like-minded professional colleagues, and attend sessions and exhibitions describing the latest research. Additionally some universities offer programs (on-site or online) that have more flexible schedules 
to allow people to pursue additional training or postgraduate degree programs without impacting their current employment responsibilities, and most recently the Institute of Food Technologists has started offering the Certified Food Scientist credential.

As mentioned previously the growing popularity of television shows describing food composition, preparation, and production have expanded the interest in food science to the mainstream public. The success of these shows will demand greater communication skills in the future so food scientists can translate and communicate highly technically complex topics in food science into consumer friendly language. Additionally, food scientists are increasingly asked to help guide those charged with public policy as it relates to topics of food, nutrition, safety and the environment.

\section{Research Our Bridge to the Future}

Research provides new knowledge which is the foundation for innovative solutions to challenges in the future. From a global perspective, we will continue to have more people who seek high-quality food due to projected population growth but with less arable land, water, and other resources available. According to the United Nations World Food Program, 795 million people (approximately one of nine people on earth) do not have enough food to live a healthy active lifestyle. Additionally, according to a United Nations FAO study, one-third of all food produced for human consumption is lost or wasted globally which amounts to 1.3 billion tons per year (Gustavsson et al., 2011). Changing consumer trends demand that our foods be safer, more environmentally sustainable, and healthier.

Through food product and process research we can continue to gain new fundamental knowledge to help us develop more efficient processes to reduce waste and natural resource consumption, improve our ability to more consistently produce foods of high product quality and improved shelf life, and create new products for a changing and demanding marketplace. Today partnerships between research providers and research sponsors are more critical than ever to insure the flow of the innovation pipeline. In addition to the direct output of new scientific knowledge, oftentimes, students receive valuable advanced level training and become the next generation of scientific leaders. Hence, public agencies, foundations, and private entities all have a stake at insuring that food research remains vibrant. Additionally, as new research techniques are developed in the basic sciences, food scientists will need to investigate ways to utilize these techniques to improve their capabilities to explore unanswered questions about the complexities of food and food processes.

While the challenges of producing the food to feed the world appear daunting, empowering food scientists through education, research, and professional development provides a clear pathway toward a safe, nutritious, wholesome food supply for all.

\section{References}

Gustavsson, J., Cederberg, C., Sonesson, U., van Otterdijk, R., Meybeck, A., 2011. Global Food Losses and Food Waste - Extent, Causes and Prevention. Food and Agriculture Organization of the United Nations. http://www.fao.org/fileadmin/user_upload/suistainability/pdf/Global_Food_Losses_and_Food_Waste.pdf.

Hardy, A., 1999. Food, hygiene, and the laboratory. A short history of food poisoning in Britain, circa 1850-1950. Soc. Hist. Med. 12 (2), $293-311$.

Iwaoka, W., 2011. Introduction to the IFT 2011 resource guide for approval and re-approval of undergraduate food science programs. J. Food Sci. Educ. 10, 54-56.

Institute of Food Technologists, 2011. 2011 Resource Guide for Approval and Re-approval of Undergraduate Food Science Programs. http://www.ift.org/community/students/ approved-undergrad-programs/undergraduate-program-resources.aspx.

Livingston, G.E., 1972. Food science graduate programs: current trends. Food Technol. 40 (9), 7-8, 11, 13-14.

Potter, N.N., Hotchkiss, J.H., 1986. Food deterioration and its control. In: Food Science. Chapman and Hall, NY. 